\title{
Smart Contracts \\ Reducing Risks in Economic Exchange with No-party Trust?
}

Eenmaa-Dimitrieva, Helen; Schmidt-Kessen, Maria Jose

Document Version

Accepted author manuscript

Published in:

European Journal of Risk Regulation

DOI:

10.1017/err.2019.37

Publication date:

2019

License

CC BY-NC-ND

Citation for published version (APA):

Eenmaa-Dimitrieva, H., \& Schmidt-Kessen, M. J. (2019). Smart Contracts: Reducing Risks in Economic Exchange with No-party Trust? European Journal of Risk Regulation, 10(2), 245-262.

https://doi.org/10.1017/err.2019.37

Link to publication in CBS Research Portal

\section{General rights}

Copyright and moral rights for the publications made accessible in the public portal are retained by the authors and/or other copyright owners and it is a condition of accessing publications that users recognise and abide by the legal requirements associated with these rights.

Take down policy

If you believe that this document breaches copyright please contact us (research.lib@cbs.dk) providing details, and we will remove access to the work immediately and investigate your claim. 


\section{Smart Contracts: Reducing Risks in Economic Exchange with No- party Trust?}

\section{Helen Eenmaa-Dimitrieva, and Maria Jose Schmidt-Kessen}

Journal article (Accepted manuscript*)

\section{Please cite this article as:}

Eenmaa-Dimitrieva, H., \& Schmidt-Kessen, M. J. (2019). Smart Contracts: Reducing Risks in Economic Exchange with No-party Trust? European Journal of Risk Regulation, 1a2), 245-262.

https://doi.org/10.1017/err.2019.37

\section{This article has been published in a revised form in European Journal of Risk Regulation https://doi.org/10.1017/err.2019.37.}

This version is published under a Creative Commons CC-BY-NC-ND. No commercial re-distribution or re-use allowed. Derivative works cannot be distributed. (0 Cambridge University Press.

* This version of the article has been accepted for publication and undergone full peer review but has not been through the copyediting, typesetting, pagination and proofreading process, which may lead to differences between this version and the publisher's final version AKA Version of Record. 


\title{
Smart Contracts: Reducing Risks in Economic Exchange with No-Party Trust?
}

\author{
Helen Eenmaa-Dimitrieva and Maria José Schmidt-Kessen
}

\begin{abstract}
Our study on smart contracts, self-executing agreements based on blockchain technology, can be placed in the field of inquiry within law and economics of contracts which explores new modes of contract enforcement as sources of market creation. We lay the foundations by characterising contract enforcement and trust mechanisms underlying contracts. Considering that trust reduces risks in economic exchange, we explain how the particular trust mechanism underlying smart contracts' enforcement (no-party trust) provides opportunities for creating new markets and changing existing ones. Among else, we explore whether using smart contracts could be a path to increase the autonomy of consumers and offer a solution for democratising trade.
\end{abstract}

Keywords: law and economics, markets, contract law, smart contracts, trust, no-trust environment, enforcement, relational contracts

Author Details: Helen Eenmaa-Dimitrieva (JSD Yale Law School) is a Postdoctoral Researcher in Information Technology Law at the University of Tartu. Maria José Schmidt-Kessen (PhD European University Institute) is an Assistant Professor at the Copenhagen Business School.

Acknowledgements: The authors are grateful to Roger Brownsword for an e-discussion which inspired them to write this paper and to Karen Yeung, Giovanni Sartor, and Hans Micklitz for drawing attention to the philosophical foundations of their work. They would equally like to thank the organizers and audiences of the conference on 'Blockchain, Public Trust, Law and Governance' at the University of Groningen in 2018 and the inaugural conference 'Constitutional Challenges in the Algorithmic Society' of the IACL Research Group on Algorithmic State, Society and Market Constitutional Dimensions in Florence in 2019. They acknowledge the generosity of the European University Institute that provided them an excellent research and teaching environment, as well as the Dora Plus programme (funded by the European Regional Development Fund) that supported their research. 


\section{Introduction}

Trust fuels markets. It is an essential component in economic exchange. ${ }^{1}$ Two parties engage in market-based cooperation if they trust that each party's obligations will be fulfilled or expect that the possible gains are greater than the potential risks arising from that relationship. As a relatively broad concept, it goes beyond interpersonal trust. Instead of a particular relationship with any of the contracting parties, trust may build on reliance on a normative system or a form of enforcement. In this paper, we inquire what kind of trust underpins smart contracts (SC) and under which circumstances SC (with their corresponding trust type) could reduce risks to such an extent that parties would enter into novel forms of economic exchange which would not be possible in the absence of SC.

While SCs could be built in various ways, ${ }^{2}$ we limit our current discussion those that operate on blockchains. Blockchain, a hash-chain coupled with timestamping technology, is a tool for preserving the integrity of data. ${ }^{3}$ It has also been viewed as a tool for facilitating verifiable value exchanges over computer networks which can be enforced with or without central institutions. ${ }^{4}$ SCs are computerised protocols that are able to enforce or execute contractual terms, e.g. could be set to

\footnotetext{
${ }^{1}$ It is reasonable to ask whether trust is necessary for economic exchange at all. For example, some could suggest that we should rather talk about the reliability of relationships or control gained over exchanges by various means instead. For studies showing that trust is essential for economic exchange and increases the efficiency of exchange due to the fact that it reduces the expectation of opportunistic behaviour which in turn lowers transaction costs, see: Kenneth Arrow, The Limits of Organization (Norton 1974); Philip Bromiley, Larry Cummings, 'Transaction costs in organizations with trust' in Robert Bies, Blair Sheppard, and Roy Lewicki (eds), Research on Negotiation in Organizations (JAI Press 1995); George John, 'An empirical investigation of some antecedents of opportunism in a marketing channel' (1984) 21 Journal of Marketing Research 278; Jay Barney, Mark Hansen, 'Trustworthiness as a source of competitive advantage' (1995) 15 Strategic Management Journal 175. We would like to bracket this debate for now by recognising that it is possible to characterise the mechanisms underlying economic exchanges with a variety of concepts. Reliance on the broad conception of trust in this paper helps us to convey a comparative understanding of various contracts, including SC.

2 For an overview of various underlying technologies upon which one could build smart contracts, see Lauren Scholz, 'Algorithmic Contracts' (2017) 20 Stanford Technology Law Review 128; Harry Surden, 'Computable Contracts’ (2012) 46 UC Davis Law Review 629.

${ }^{3}$ As a tool for preserving the integrity of data, blockchain has been around for decades already. It is not suitable as a solution for achieving the much-desired confidentiality of information (not just data) or its verifiability. After all, whether something recorded on the blockchain corresponds to the actual facts in the world (i.e. whether it is true or not) is not only a matter of verifying whether a piece of data has been recorded in a particular database. It also concerns the real-world circumstances connected to the information that the data is meant to confer (the particulars about the people, items, information or values involved). See e.g. Ahto Buldas, Peeter Laud, Helger Lipmaa, Jan Villemson, 'Time-stamping with binary linking schemes' 1462 LNCS. Lecture Notes in Computer Science 486; Ahto Buldas, Helger Lipmaa, Berry Schoenmakers, 'Optimally Efficient Accountable Time-Stamping' (2000) 1751 LNCS. Lecture Notes in Computer Science 293.

${ }^{4}$ See e.g. Helen Eenmaa-Dimitrieva, Maria José Schmidt-Kessen, 'Creating Markets in No-Trust Environments: The Law and Economics of Smart Contracts' (2018) 35 Computer Law \& Security Review 69; Scholz, supra, note 2, 145-148.
} 
trigger an action from a contractual relationship. ${ }^{5}$ As contracts, they are distinct due to their selfexecuting and self-enforcement capability: the code is there to define the contract and to automatically trigger and enforce it. ${ }^{6}$ This means that once the contract is concluded, its preprogrammed enforcement takes place according to the algorithm, being to an important extent independent of external influence or control. ${ }^{7}$

As we discuss below, while trust between contracting parties or in the related community is always an asset in economic exchange, SCs on public blockchains introduce a particular kind of trust mechanism which allows the exchange to happen without trust between the parties or in the community. SC have the capacity to create a new form of trust that we term no-party trust. ${ }^{8}$ We explain how and describe scenarios in which the particular trust mechanism underlying the enforcement mechanism of SC provides opportunities for creating forms of economic exchange.

We proceed by first examining various institutions and technology as sources of trust in Section II. In Section III, we explain how these various sources of trust can enhance economic exchange. In Section IV we describe the characteristics of SC on public blockchains that could enable economic exchange in a way in which none of the other sources could. Lastly, in Section V, we discuss which novel forms of economic exchange could be generated by no-party trust provided by SC on public blockchains.

\section{Institutions and Technology as Sources of Trust}

Trust is one of the human mechanisms to deal with risk. It is often described via two components: (1) willingness to be vulnerable, i.e. the willingness to assume risk in relation to the actions of a trustee (a person, an institution, a mechanism, a system etc.), and (2) positive expectations regarding other parties' actions or a particular outcome. ${ }^{9}$ By trusting a person, an entity, or the context in which we operate, we form a set of confident, positive expectations regarding someone's conduct, motives, and intentions in situations entailing risk; these expectations create a willingness to act on the basis of the words, actions, and decisions of the trustee. ${ }^{10}$ Along these lines, trust has been viewed as "one's expectation that another will act in a way that is advantageous to oneself,

\footnotetext{
5 Andrej Savin, 'Blockchain, Digital Transformation and the Law: What Can We Learn from the Recent Deals?’ Presented at CBS Maritime Law Seminar Series on March 22, 2018.

6 Scholz, supra, note 2, 145-148.

7 While the automated enforcement of SCs can be essentially independent of external influence or control, the parties may choose to involve external information sources known as oracles in the process of execution, or separate the execution process into several stages with varying levels of parties' involvement. The level of external control in particular SC depends on the contents of the contract.

${ }^{8}$ Eenmaa-Dimitrieva, Schmidt-Kessen, supra, note 4.

9 Roger Mayer et al., 'An integrative model of organizational trust' (1995) 20 Academy of Management Review 709; Jason Colquitt, Jessica Rodell, 'Justice, Trust, and Trustworthiness: A Longitudinal Analysis Integrating Three Theoretical Perspectives’ (2011) 54:6 Academy of Management Journal 1183.

${ }^{10}$ Colquitt, Rodell, supra, note 9.
} 
supplemented by one's availability to act upon such expectation, accepting the corresponding risks". ${ }^{11}$

Trust in people and people as sources of trust. Trust has often been defined as a feature of people's interaction with one another. One the one hand, people rely on personalised trust, i.e. trust regarding particular person's actions which has developed through repeated interactions (e.g. with a colleague, trading partner, or a family member). ${ }^{12}$ On the other hand, people rely on generalised trust, i.e. the trust that they have toward a random member of an identifiable group (e.g. a representative of an organisation like a bank, or a profession like a doctor). ${ }^{13}$ Individuals and groups can be involved in the production of trust that others might have in them, for example through developing their reputation, stating their values, belonging to a network, or interacting with one another.

Trust in institutions and institutions as sources of trust. In a similar manner, trust is also a feature of people's interaction with institutions or inter-institutional relations. One might have a certain level of trust towards an institution (e.g. law, community, organisational norms), or the environment created by it (e.g. a legal or community environment) along the lines of personalised or generalised trust in people. An institutional environment could also provide grounds for further trust. A variety of institutions or normative environments (e.g. law or a set of community norms) contribute to the interaction among individuals and organisations due to enabling new relationships which are almost independent of the characteristics of the particular parties.

(1) They make it easier for parties to decide to enter into a relationship with each other and rely on the other. The fact that the relationship would exist in a supportive environment characterised by some level of certainty about applicable procedures and consequences or sanctions, provides sufficient grounds for the parties to decide to step into that relationship independent of evaluating the level of trust they have towards the particular party. The institutional environment helps to coordinate the applicable norms in an efficient manner, thereby backing up even trust that might exist between parties before, for example in a multi-faceted personal and community based relationship. In other words, the institutional set of norms might serve as an incentive for a party to enter an agreement because a party might perceive that set of rules as an added safety measure or as protection against risks.

(2) They enable parties to enter into relationships on the basis of a minimal level of acquaintance and accordingly minimal level of trust towards the other party. While trust between contracting parties or in the related community is always an asset, the guarantees inherent in the institutional environment allow parties to have sufficient level of certainty about the outcomes of the relationship even when they do not know the other party.

11 Giovanni Sartor, 'Privacy, Reputation, and Trust: Some Implications for Data Protection' EUI working paper LAW No. 2006/4.

12 Avner Greif, 'Contract Enforceability and Economic Institutions in Early Trade: The Maghribi Traders' Coalition' (1993) 83 American Economic Review 525; Luigi Guiso et al., 'Cultural Biases in Economic Exchange?' (2009) 124:3 The Quarterly Journal of Economics 1095.

${ }^{13}$ Bill McEvily et al., 'Can Groups Be Trusted? An Experimental Study of Collective Trust' in Reinhard Bachmann and Akbar Zaheer (eds), The Handbook of Trust Research (Edward Elgar 2006); Luigi Guiso et al., 'The Role of Social Capital in Financial Development' (2004) 94 American Economic Review 526. 
Both of these are consequences of the parties' awareness that others are bound by that environment (too) and are, accordingly, either more likely to act according to what the applicable norms require, or are subject to the sanctions that the environment prescribes. ${ }^{14}$ In economic terms, we would say that this is one way in which institutions are able to reduce transaction costs.

While the particular institutional environments (law, a set of community norms) might make it easier for parties to develop trust towards each other, this does not capture the entire story why parties decide to enter into risky relationships. It is not exclusively the trust between the parties that matters for the creation of these relationships, but also the trust towards the particular environment and its institutions. ${ }^{15}$ Dasgupta, for example, explains that there is a strong interconnection between trust among persons and enforcement agencies (as one form of institution), and that trust in institutions directly influences trust in other persons. 16 If a person does not have trust in an enforcement agency, she will be less likely to trust persons to fulfill their obligations under a contract. ${ }^{17}$ This can deter her from entering into a contract in the first place. ${ }^{18}$ A supportive environment characterised by some level of certainty about applicable procedures and consequences/sanctions encourages parties to enter into a relationship with each other by reference to their ability to rely on these mechanisms in the particular environment. Therefore, trust towards another party can be fostered by an institutional environment, but this presupposes trust in the environment itself.

Trust in technology and technology as a source of trust. The discussion of trust between parties and institutions has been accompanied by the recognition that one could also trust a technological environment i.e. rely on the proper functioning of a technological system. As Lynne Zucker suggested, "[W]e would not make use of technological systems and of the corresponding sociotechnical infrastructures unless we had some trust in their proper functioning, and in the correctness and loyalty of their administrators." 19 As trusted environments, certain technological systems (like a computerised protocol of SC) could also facilitate contracting.

Just like institutions (e.g. a legal system), technology can support relationships by creating a supportive environment characterised by some level of certainty about applicable procedures. Automated procedures characteristic of self-enforcing agreements like SC are just one example: they help parties to achieve their goals without allowing them to alter the automated process in the

\footnotetext{
${ }^{14}$ A similar idea has been defended by several authors. E.g.: Sartor, supra, note 11; Daniela Memmo et al., 'Trust, Reliance, Good Faith and the Law' in Paddy Nixon, Sotirios Terzis (eds), Trust Management (Springer 2003) 150-64.
}

15 Kenneth Arrow, for example, notes that the trust relationship between a patient and her doctor derives from the fact that society imposes a certain code of conduct on doctors (e.g. that the doctor is using her knowledge to the best advantage of the patient, and that the doctor is not after maximising her income with the patient) that gives the patient trust in the doctor independently from the person of the doctor. See Kenneth Arrow, 'Uncertainty and Medical Care' (1963) 53:5 American Economic Review 941, 965.

16 Partha Dasgupta, 'Trust as a Commodity' in Diego Gambetta (ed), Trust: Making and Breaking Cooperative Relations (Blackwell 1988) 49.

17 Ibid.

18 Ibid

19 Sartor, supra, note 11. 
middle. Trust in the technology providing the automation facilitates contracting on the basis of a minimal level of acquaintance with the other party. Just like in a legal or community environment, this implication arises from the parties' awareness that the other party is bound by that same technological environment too and is, accordingly, subject to the automation, procedures and sanctions that the environment prescribes. Parties enter into a relationship because of the role that technology underlying SC plays in it, namely that it directs the actions of another actor and limits their range.

While we primarily focus on this kind of trust in technology in this paper, let us also look into how technologies could create or reinforce trust between parties (individuals or institutions). If we have a sufficiently reliable technology, it is likely to enhance trust towards individuals or institutions, for example, when those institutions or people employ such a technology in their interaction with others. In other words, certain technologies, just like institutions or individuals themselves, can be involved in the production of trust. Following Zucker's influential account on trust as a good that can be manufactured and purchased, we also see how "one type or source of trust can substitute for another under some conditions." 20 Accordingly, there are grounds for considering the possibility that among the sources of trust, technology might substitute institutions or individuals. For example, technologies can support the generation of trust, e.g., by allowing people to verify the acts of the authorities (e.g. via logs), providing reliable process for questioning the permissibility of these acts (e.g. via procedural guarantees), and allowing people to communicate with institutions on equal terms with everyone else regarding the exercise of authority. The technology underlying blockchain could possibly support the generation of such trust by guaranteeing the integrity of data and allowing the verification of its submission by allowing access to the hash-chain that has been generated over time. ${ }^{21}$ By being a reliable technology, it could not only be used to enhance trust between individuals or institutions but also create or reinforce trust in a variety of technologies (e.g. the long-term reliable use of blockchain in governance could support trust in the technology underlying Bitcoin or various other applications of blockchain technologies).

\section{Sources of Trust in Economic Exchange}

Do we trust technology in the same manner as we trust institutions, or do they have characteristics that make them distinct from each other? Does the technology underlying SC support trade in a similar manner as other institutional environments do?

Economic exchange and trade in all its forms rely on trust, be it trust towards a person, an institution, or an environment created by an institution or a technology. Posner has claimed that

\footnotetext{
20 Lynne Zucker, 'Production of Trust: Institutional Sources of Economic Structure: 1840 to 1920' in L. L. Cummings, Barry Staw (eds), Research in Organizational Behavior (JAI Press 1986) 55-111.

21 On this point, see also Christian Catalini, Joshua Gans, 'Some Simple Economics of the Blockchain' MIT Sloan Research Paper No. 5191-16 (21 September 2017) <https://papers.ssrn.com/sol3/papers.cfm? abstract $\mathrm{id}=2874598>$ accessed 31 October 2018.
} 
trust is merely an imperfect substitute for information.22 Just like information, it reduces the perceived risks. As long as perfect information is unavailable to us, trust maintains an influential role in relationships, including economic ones. When people think that there is too high risk of being cheated, they will refrain from engaging in economic transactions. ${ }^{23}$

Contracting is one way to enter into such an exchange and this supports trade. 24 In case of mutual agreements, or contracts, there are enforcement mechanisms that provide some guarantees for the execution of contracts and thus make contractual relationships more predictable and reliable. Enforcement mechanisms rely on various trust mechanisms: (i) based on the parties' internal value systems, (ii) based on a set of community customs or norms, (iii) based on enforcement by a third party vested with state authority, and (iv) a possible further type that differs from all the previous options, which we term no-party trust. While Dixit has distinguished between first-, second- and third-party methods of private contract governance, we show how the same distinctions can be illuminating for the current discussion. ${ }^{25}$ This also helps us to situate Werbach's concepts of peerto-peer and Leviathan trust in the economic discourse on contracts. ${ }^{26}$

We briefly explain the characteristic features of each type of trust as well as how we can distinguish between contracting environments on the basis of their contract enforcement mechanisms, which in turn rely on the distinct kinds of trust mechanisms for mitigating risks. We do this in order to discuss the trust mechanism that technology generates for supporting economic exchange. With the rise of new technologies like public blockchain based SC, should we speak of a new fourth type of trust mechanism in the governance of contracts? And what are its unique characteristics that differentiate it from the other three types of trust?27

\footnotetext{
22 Richard Posner, 'The Right of Privacy' (1977) 12:3 Georgia Law Review 393, 408; see also Arrow, supra, note 15 . We thank our reviewer for making the point that the reverse can be true, too: information duties imposed under contract law obliging parties to reveal information are a means to mimic or even foster trust. While literature on the imposition of information duties in EU contract law rather stresses the function of information duties as either a tool of market regulation to cure information asymmetries between parties or to enhance private autonomy (e.g. David Kästle-Lamparter, 'Section 4: Pre-contractual Information Duties' in Niels Jansen \& Reinhard Zimmermann (eds), Commentaries on European Contract Law (OUP 2018), 383-504, 402-403) they could, of course, ultimately lead to more trust between parties. Nonetheless, trust always has a definitional element of uncertainty about how other people will behave, therefore, perfect information would likely do away with trust altogether. As put by Gambetta, 'For trust to be relevant, there must be the possibility of exit, betrayal, defection'. See Diego Gambetta, 'Can We Trust Trust?'in Diego Gambetta (ed), Trust: Making and Breaking Cooperative Relations (Blackwell 1988), 213-237, 218-219.

23 Dasgupta, supra, note 16; Avinash Dixit, 'Governance Institutions and Economic Activity' (2009) 99 American Economic Review 5.

24 An alternative would be to set up a company/firm.

${ }^{25}$ The concept of second and third-party institutions and governance are discussed in Dixit, supra, note 23.

26 We use the concepts of peer-to-peer and Leviathan trust to cover the same idea or institutional phenomenon as discussed in the widely circulated draft paper by Kevin Werbach, 'Trustless Trust' $<$ https:// ssrn.com/abstract $=2844409>$ accessed 14 August 2017, 4 .

${ }^{27}$ We engage to a certain extent with these questions in Eenmaa-Dimitrieva, Schmidt-Kessen, supra, note 4.
} 
Trust based on individuals' internal value systems. In case of first-party trust, as put forward by Dixit in a more general manner for what he terms 'first-party systems', ${ }^{28}$ parties entering into an economic transaction trust that the other party will not behave opportunistically due to their internal value system that has developed through socialisation within the family, school, and other educational institutions. ${ }^{29}$ Based on their internal value system, parties opt to make themselves vulnerable to potential risks on the basis of the expectation that the values that the other party holds and the likelihood that acting contrary to those values would disturb their conscience reduces the possible risks in the relationship.

Trust based on a set of community customs or norms. In case of second-party systems ${ }^{30}$ or peerto-peer trust, ${ }^{31}$ parties entering into an economic transaction opt to make themselves vulnerable to potential risks on the basis of the expectation that the other party will not behave opportunistically because of norms specific to a community to which both parties belong that will drive both parties to fulfill their obligations. Peer-to-peer trust environments are usually difficult to extend beyond the ties that develop through repeated interactions or that exist in close-knit communities with a common set of values such as a trade or profession, families or religious groups ${ }^{32}$. The main incentive to comply with one's obligations is the fear of losing reputation in the eyes of the other community members. This trust type can be found in so-called relational contracting. ${ }^{33}$

Trust based on a third party vested with state authority. Third-party systems ${ }^{34}$ or Leviathan trust architectures $^{35}$ refer to trust that builds on centralised coercive power, such as institutions of government, including courts. While we do not think that law or legal systems usually operate like Hobbesian Leviathans or can be explained by the command theory, we do want to rely on Werbach's label which conveys the idea that, broadly, we can distinguish a large group of normative systems where rules (including those about contractual obligations) can be enforced with the actual or threatened use of coercive force. 36 The legitimacy conditions of such systems is another, although also vastly important matter.

The incentive for two parties to engage in economic exchange in a Leviathan trust environment is less provided by a fear of losing one's face vis-a-vis the community, but by the reliable assumption

${ }^{28}$ Dixit, supra, note 23. Dixit refers here also to Roland Benabou, Jean Tirole, 'Intrinsic and Extrinsic Motivation' (2003) 70:3 Review of Economic Studies 489.

${ }^{29}$ Dixit, supra, note 23, 11-12.

30 Ibid.

${ }^{31}$ This term is coined by Werbach based on Elinor Ostrom's conceptual work. See Werbach, supra, note 26, 4; Dixit, supra, note 23, 13.

32 Werbach, supra, note 26, 16.

33 Important foundational works for relational contract theory within the area of law are Stewart Macaulay, 'Non-Contractual Relations in Business: A Preliminary Study.' (1963) 28 American Sociological Review 55; Ian Macneil, 'Relational Contract: What We Do and Do Not Know' (1985) 4 Wisconsin Law Review 483.

${ }^{34}$ Dixit, supra, note 23, 14-15.

35 Werbach, supra, note 26,6 .

${ }^{36}$ We thank Karen Yeung for drawing attention to our label. 
that the central coercive authority can enforce obligations or impose sanctions. Parties are thus willing to make themselves vulnerable ex ante, relying on the practice that if the other party defaults at a later point in time, there will be a sanction. ${ }^{37}$ The near certainty of this sanction will drive parties to fulfill their obligations in the first place. The prime example of a Leviathan trust mechanism would be the conclusion of a contract with the knowledge that a court would enforce it based on contract law.

Certain private actors operating as intermediaries can also generate a form of Leviathan trust when they have the power to enforce contracts between external parties transacting through them. They can even provide guarantees for the performance of obligations themselves, or remedies for nonperformance. One example of this would be eBay's chargeback function for transactions conducted on the platform. 38

No-party trust mechanism. Where enforcement through law or social relations is unavailable or inconvenient, is a reliable economic exchange also precluded? Not necessarily. In no-trust contracting environments parties meet in anonymity and there are weak or no formal contract law or institutionalised intermediaries for ensuring the enforcement of contracts. 39 While in legal or relational contracting environments we rely, respectively, on enforcement through law or social relations, in a no-trust contracting environment such an option is not available. Instead, we might be able to rely on enforcement through technology (eg via SC).

This study has two potential paths. While we could take a sociological turn, asking which mechanisms in general, including alternatives to trust, ground the economic exchange that is happening via blockchain based contracts, we are currently interested in asking a different question. Namely, could such economic exchange overall occur without trust between parties (firstparty, or peer-to-peer), trust in the community setting (peer-to-peer) or trust in the central authority/ intermediary (Leviathan)? And if so, how? When asking this question, we rely on the previously discussed ideas that trust is an essential component in economic exchange, and just as we can trust a person or an institutional environment, we can trust a technological system thanks to its provision of sufficient certainty about applicable procedures. We have to keep the discussion mainly at a theoretical level because there is no large-scale use of SC based on public blockchains yet that would allow the gathering of solid empirical evidence.

As we know, open and permissionless blockchain applications like Bitcoin and Ethereum were indeed intended to operate in an environment where "the participants in the network need not trust each other". ${ }^{40}$ Kevin Werbach has suggested that such technologies could support trade through the

\footnotetext{
37 This is the basic game theoretical explanation found in any law and economics textbook for why contract law exists, e.g. Robert Cooter, Thomas Ulen, Law and Economics (6th ed, Pearson 2012), 284.

38 On chargeback mechanisms used by online intermediaries, see Yue Guo, 'To Sell or Not to Sell Exploring Sellers' Trust and Risk of Chargeback Fraud in Cross-border Electronic Commerce' (2018), 28 Information Systems Journal, 359.

39 Eenmaa-Dimitrieva, Schmidt-Kessen, supra, note 4.

40 Jean Bacon et al., 'Blockchain Demystified' (2017) Queen Mary School of Law Legal Studies Research

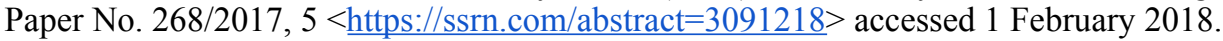


trust mechanism that he coins as 'trustless trust'. ${ }^{41}$ To avoid an oxymoron, we might also call it noparty trust. In essence, it highlights the reliability of technology as the feature that supports contracting in environments where there are none of the existing trust mechanisms facilitating trade. How would the no-party trust mechanism facilitate contracting and thereby support economic exchange?

In a traditional legal contracting environment the contract enforcement is ultimately based on the central authority and its coercive power. Contracting is characterised and fuelled by the Leviathan trust mechanism, e.g. trust in the legal environment (institution of law), which on the one hand, helps to enforce the terms of the contract, and on the other hand, provides a reliable and coordinated normative system which makes it easier for parties to enter relations with each other.

In relational contracting environments, the contract enforcement is based on interpersonal relations and community norms. Contracting is characterised and fuelled by peer-to-peer trust, i.e. trust in the relational environment or community, which on the one hand, encourages the other party to perform their contractual obligations, and on the other hand (as in a legal environment), provides a system of coordination which makes it easier for parties to enter relations with each other.

In no-trust contracting environments (characterised by anonymity and unavailability of legal or relational contract enforcement mechanisms) technology based enforcement is one method to support contracting (blockchain and SC are just some of the options). Such contract enforcement would rely on no-party trust, i.e. the parties opt to make themselves vulnerable to the potential risks of the relationship based on the expectation that the technological environment provides certainty about applicable procedures, including, for example, automated enforcement of the contract in case of SC. In case of such an enforcement mechanism parties have very limited options not to perform their contractual obligations, and (as in a legal and relational environments) thanks to providing a system of coordination the underlying trust mechanism makes it easier for parties to enter relations with each other.

There are also, of course, contracting environments where legal or relational contract enforcement mechanisms are available for large players, but not for small players. We could call these unequal or undemocratic contracting environments because they preclude small players from participating. In these cases, technology-based (e.g. automated) contract enforcement could allow transactions to take place among more small players than currently possible due to the reduction in transaction costs. We see the same trust mechanism at play here as in the scenario above. By providing a reliable and coordinated system, such a technology makes it easier for the small players to enter into economic exchange. The small players could opt to make themselves vulnerable to the potential risks on these markets on the basis of the expectation that the technological environment counters the risks via the constraining power of automated enforcement.

It is plausible that trust in the general operation of the contracting environment and its underlying mechanism of enforcement plays a significant role in decisions regarding when and under what circumstances to enter into relations with another party in the particular contracting environment. Trust in the contracting environment, as we call it, is essential to such decisions. Of course, it is not necessarily the only kind of trust that plays a role. In all of the scenarios above, exchange can be

\footnotetext{
${ }^{41}$ See Werbach, supra, note 26; Kevin Werbach, 'Trust, But Verify: Why the Blockchain Needs the Law' (2018) 33:2 Berkeley Technology Law Journal 487.
} 
facilitated by other types of trust as well. For example, it could be increased by personalised trust towards the identified other party (perhaps thanks to prior repeated interactions) or generalised trust towards a member of an identifiable group (perhaps thanks to repeated interaction with members of that group or deeper familiarity with it). Of course, in the case of negative experiences with the identified other party or members of the identifiable group the level of trust in the contracting environment could also be decreased.

\section{Smart Contracts as Sources of No-Party Trust for Economic Exchange}

Which would be the characteristics of SC based on public blockchain that would generate the new 'no-party' trust type that could not be replicated by all other trust mechanisms? Essentially, four specific features of public blockchains would constitute no-party trust in the case of SC on public blockchain: (i) automated performance, (ii) the consensus mechanism and cryptographic proof of transactions, (iii) transparency, and (iv) decentralisation.

One feature of public blockchain is that the identity of the parties transacting over them can remain to a large extent anonymous, for example through using cryptographic authentication ${ }^{42}$ to validate transactions. While it is not impossible to trace an identity back to a specific user, ${ }^{43}$ none of the usual data that we give away when contracting online (personal data, credit card data, etc.) need to be transmitted in a blockchain transaction. If we follow the theoretical argument on various trust mechanisms of the previous sections, engaging in economic exchange in anonymity, without any hint about the identity of the other party, would be very unlikely to occur between parties with an average risk profile because none of the traditional trust mechanisms (first, second, third-party trust) would be in place to sustain such an exchange. The four features of public blockchain mentioned above, however, could allow for such contracting to occur because they have the potential of generating no-party trust.

First, there is the automated performance of SC on public blockchains. As explained, for example by Raskin, ${ }^{44}$ automation of contract performance means that parties enshrine the terms of their contract in computer code, which has control over the digital or physical assets that are subject to the execution of the contract. This computer code is then placed on the public blockchain after having been validated in the consensus process, which we discuss next. From this moment onward, the contract is self-enforceable in the sense that it automatically executes when the conditions of the contract have been met, and none of the parties can interfere in this process. ${ }^{45}$ Due to the

\footnotetext{
42 Public Key Infrastructure (PKI) is one of the possible authentication mechanisms based on cryptography and is used both for the Bitcoin and the Ethereum blockchain. For a more detailed explanation of PKI see, e.g., Bacon, supra, note 40.

43 There is a lot of research showing that at least of the Bitcoin blockchain, PKI does not provide any meaningful level of anonymity. See Sara Meiklejohn et al., 'An Empirical Analysis of Anonymity in Zcash' (2018), <https://smeiklej.com/files/usenix18.pdf> accessed 12 April 2019.

44 Max Raskin, 'The Law and Legality of Smart Contracts' (2017) 1 Georgetown Law and Technology Review 305, 309-310< https://papers.ssrn.com/sol3/papers.cfm?abstract_id=2959166> accessed 12 April 2019.

${ }^{45}$ Raskin, supra, note 44, 311.
} 
limiting or elimination of the parties' options not to comply with contractual terms, parties do not need to rely on any trust mechanism, other than trust in the technology (i.e. no-party trust).

Second, the consensus mechanisms for public blockchains is important in the creation of no-party trust. Blockchains operate as distributed public records of events, spread and synchronised across nodes 46 in which each and every transaction occurring between blockchain participants is recorded. ${ }^{47}$ Each time a new block of valid transactions in regard of a SC is added to the ledger, it needs to go through a validation process where various so-called 'miners' engage in a competition to solve a cryptographic puzzle first in order to add a block of transactions to the chain. ${ }^{48}$ Miners are rewarded for every block they validate. Since a block with invalid transactions would be rejected by the network and would thus not yield any reward to the miner, miners have no incentive to try and add a block with invalid transactions to the chain. ${ }^{49}$ While miners could be considered as a centralised enforcer, the network protocol constrains them so much in their preferences (they will only mine valid transactions) that parties do not need to trust them. Again, this gives us another piece of no-party trust generated by blockchain technology.

In addition, the task of the miners is to apply a hash function to the contents of a block. ${ }^{50}$ Hashing involves the creation of a unique identifier for the combination of data contained in a block and helps to preserve the integrity of that data. ${ }^{51}$ The hash value of the block changes with any change in the record of events and this allows to identify any interference. ${ }^{52}$ Parties thus know that they will immediately learn when there was any form of unauthorised interference with their SC, again eliminating an element of uncertainty that would otherwise need to be bridged by trust to allow for economic exchange.

Third, transparency contributes to no-party trust. Since participants to a public blockchain could have the option to see all transactions that have occurred on a blockchain, ${ }^{53}$ and the source code of

\footnotetext{
${ }^{46}$ Node usually refers to a single computer in a network of computers. In the case of blockchains, the node is a computer that stores a copy of the blockchain. In public blockchains any node can participate in the consensus mechanism. See, e.g., Primavera De Filippi and Aaron Wright, Blockchain and the Law:

The Rule of Code (Harvard University Press 2018) 36.

47 Joseph Bonneau et al., 'SoK: Research Perspectives and Challenges for Bitcoin and

Cryptocurrencies' (2015) 2015 IEEE Symposium on Security and Privacy (IEEE 2015).

48 Ibid..

49 Ibid.

50 Ibid.

${ }^{51}$ Bacon et al, supra, note 40, 6-7.

52 Ibid. See also De Filippi, Wright, supra, note 46, 36.

${ }^{53}$ For Ethereum, for example, all transactions having occurred so far are available on various websites, e.g. Etherscan, $<$ https://etherscan.io/txs $>$, accessed on 12 April 2019.
} 
the blockchain network protocol could be open source, 54 this would allow parties to inspect how the technology works and which transactions took place. ${ }^{55}$ This, in turn, would replace the otherwise needed trust when using non-transparent, proprietary technologies for economic exchange. 56

Fourth, public blockchains operate in a decentralised manner. This means that the ledger which records all transactions is stored and synchronised across many different nodes in the network. ${ }^{57}$ This has two consequences from a trust perspective. On the one hand, parties know that the ledger is replicated and synchronised across many different nodes which means that if one of the nodes works defectively or is disconnected, there will be many further nodes with copies of the ledger and with the capacity to execute SC. The decentralised architecture thus acts as a guarantee for the execution of SC that can arguably foster parties' trust in the technology. Secondly, the fact that no central authority can intervene in the decentralised architecture of public blockchain means that there in no need to have a trustworthy centralised authority enforcing economic exchange occurring on public blockchains via SC. ${ }^{58}$

In contrast to transactions occurring on public blockchains, it is important to stress that no-party trust might not be the mechanism underlying economic exchange on permissioned blockchains. 59 In case of small-scale permissioned systems, for example where participation is limited only to a certain group of users, "there is likely to be a higher level of trust among users, reducing the need for distributed storage and consensus protocols." 60 In such a manner, utilising a blockchain might facilitate an indirect trust mechanism between known participants and operate as a community

54 This is at least the case for the two main examples of public blockchains, Ethereum and Bitcoin. The open source software of bitcoin is called Bitcoin Core (see $<$ https://github.com/bitcoin/bitcoin $>$ accessed 13 April 2019), Ethereum is developed through an open-source process while the ultimate decisions about changes to the protocol is taken by the Ethereum Foundation, and by the Ethereum founder Vitalik Buterin (see Nick Tomaino, "The Governance of Blockchains", (2017), $<$ https://thecontrol.co/the-governance-ofblockchains-5ba17a4f5da6 $>$ accessed 13 April 2019.

${ }^{55}$ Bacon et al, supra, note 40, 21-22.

56 The classic argument for using open source software is that it is more secure since it allows anyone to inspect the source code of a program and understand how it functions. As a Reddit blogger put it in an easily understandable way: 'It's not that open source software is necessarily better engineered...it is that without the source code it is impossible to see what a program does. So open source software is seen as more secure as it is the only kind of software that can be checked for security at all without needing to blindly trust someone....everything not open-source can't be checked and by this has to be seen as insecure' (See Jim Lynch, 'Why is Open Source Software More Secure'? (2015) < https://www.infoworld.com/article/2985242/ why-is-open-source-software-more-secure.html> accessed 13 April 2019). For a more comprehensive argument why software should be open source and how copyright helps to support the open source software movement, see James Boyle, Enclosing the Commons of the Mind (Yale University Press 2008), Chapter 7.

57 Bacon et al, supra, note 40, 11-12.

58 As De Filippi and Wright explain, just as the Internet was envisioned by some activists as a space free of government intervention, so was the creation of the idea of smart contracts by cypherpunk Nick Szabo. De Filippi, Wright, supra, note 46, 7, 73.

${ }^{59}$ For a more detailed discussion on the distinction between public and private blockchains in general see, e.g., Eenmaa-Dimitrieva, Schmidt-Kessen, supra, note 4.

${ }^{60}$ Bacon et al, supra, note 40 . 
where second-party trust fosters exchange. This would also be true of SC that are concluded in such settings and bear the potential of establishing a parallel system to the state-provided legal system that is governed by its own rules.

\section{Smart Contracts and Economic Exchange}

We made the theoretical argument that SC offer a new mode for contracting in situations where no other forms of trust would facilitate economic exchange. In other words, SC could support contracting in situations where no contracting would occur (due to no trust provided by a legal system or courts enforcing contracts, a community imposing norms, or mutual knowledge of each other's value system) but for the existence of public blockchains and SC.

In economic terms, we could characterise this situation by saying that $\mathrm{SC}$ reduce transaction costs 61 to such an extent that people are willing to enter into economic relations through a market system where they were not prepared to do so in the absence of SC. ${ }^{62}$ We could therefore expect that this new form of trust has the potential to allow for contracts being concluded and new forms of economic exchange taking place.

Which type of economic exchange would increase, however, based on no-party trust? After all, a critical person might ask why anonymity in contracting combined with a very reliable enforcement mechanism would be so relevant to parties. What kind of trade would flourish under such conditions?63 A market for organ trade or trade in babies? A market for illegal drugs and weapons, illegal ivory, stolen identities, and contract killers' services? Not all types of economic exchange are desirable or good for society. ${ }^{64}$ The use of bitcoin to transfer funds for terrorism and to pay for illegal drugs on the Silk Road, for example, come to mind when considering the harmful sides that public blockchains and cryptocurrencies can have, ${ }^{65}$ and that widespread adoption of SC might have in the future. ${ }^{66}$

\footnotetext{
${ }^{61}$ For studies on such technologies through the lens of transaction cost economics see, e.g.: Catalini, Gans, supra, note 21; Sinclair Davidson et al., 'Blockchains and the Economic Institutions of Capitalism' (2018) 14:4 Journal of Institutional Economics 639-658; Antonio Nicita, Massimiliano Vatiero, 'Blockchain and incomplete rights. Whither challenges for rules and organisations' Presentation at the Annual Conference of the Italian Law and Economics Society 2017, Rome 16-17 December 2017.
}

62 This theory goes back, for example, to the works of Ronald Coase and Oliver Williamson.

63 We thank Roger Brownsword for asking this question.

${ }^{64}$ The reminder that markets are not always a good thing by definition is discussed in an enlightening way by Lisa Herzog, Inventing the Market: Smith, Hegel, and Political Theory (Oxford University Press 2013). The same point is made by Gambetta, supra, note 22, 214.

65 Aaron Wright, Primavera De Filippi, Blockchain and the Law (Harvard University Press 2018) 66.

${ }^{66} \mathrm{To}$ an extent, illegal behavior can already be observed in relation to $\mathrm{SC}$ on Ethereum that allow for gambling, see Massimo Bartoletti, Livio Pompianu 'An Empirical Analysis of Smart Contracts: Platforms, Applications and Patterns' (2017) manuscript $<$ https://arxiv.org/pdf/1703.06322.pdf $>$ accessed 31 October 2018. The authors provide empirical evidence that the second most frequent type of $\mathrm{SC}$ on the public Ethereum relate to games, including games of chance, which, since unlicensed, would be illegal in many jurisdictions. 
Apart from the risk of creating illegal markets, another type of socially harmful SC on public blockchain would be anti-competitive SC. This would be the case with SC that facilitate collusion or implement a cartel agreement. SC might, for example, be a perfect tool for a cartel because no participant in a cartel SC could follow the temptation to deviate from it ${ }^{67}$ and effective punishment mechanisms for deviation could be implemented. ${ }^{68}$ Furthermore the transparency of blockchains, in particular of public blockchains, might facilitate collusion 69 because firms can track each other's SC and pricing, making anti-competitive coordination easier. ${ }^{70}$ Features of SC and blockchains that might facilitate anti-competitive behavior, however, might equally remedied by the architecture of blockchains themselves. Given that anti-competitive behavior usually requires secrecy to avoid detection by competition authorities or other market participants that might retaliate, however, the transparency of blockchain might actually act as a deterrent for anti-competitive conduct. ${ }^{71}$ Certain design features of public blockchain might thus act as deterrents against anti-competitive agreements implemented on them.

All this being said, we should not draw conclusions about the social (un)desirability of SC on public blockchain too quickly. Many useful technologies carry both, the potential for fostering economic growth and enhancing efficiency, while also bearing significant risks leading to harm for society in case of misuse. This is true for knives (that can be used to prepare a lovely dinner, or to stab a person), cars (that can be used to go on holidays, or to perpetrate a terrorist attack), or nuclear technology (that can be used to produce clean energy or to build atomic bombs). We suggest that this is also how SCs based on public blockchains should be seen. They do not only allow for illegal trade to occur, but they could also enable new forms of economic exchange that are actually desirable.

Which new forms of desirable economic exchange that did not exist before due to a lack of trust mechanism could be potentially facilitated by SC on public blockchain? And who would be the beneficiaries? The quick answer is: we do not know yet, since there are no widespread use cases of

\footnotetext{
${ }^{67}$ Due to the fact that a cartel usually involves an agreement between firms to keep prices artificially high to reap off higher profits jointly, any of the participating firms has an incentive to lower prices in contravention of the cartel, because it would immediately attract most demand in the market.

68 Lianos, for example, envisages a smart contract between cartel members that distributes funds among cartel members could include an escrow function that would prevent the paying out of funds to a cartel member that has deviated from the cartelised price. Ioannis Lianos, 'Blockchain Competition' (September 15, 2018). in Philipp Hacker et al (eds), Regulating Blockchain: Political and Legal Challenges, OUP, 2019,

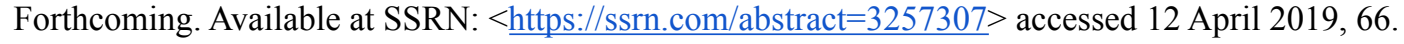

${ }^{69}$ Ibid.

70 See OECD Blockchain Technology and Competition Policy, 8 June 2018, 2.

${ }^{71}$ See for a similar analysis and conclusion in respect of unilateral anti-competitive behavior Thibault Schrepel, 'Is Blockchain the Death of Antitrust Law: The Blockchain Antitrust Paradox' (2018) Georgetown Law Technology Review $<$ https://papers.ssrn.com/sol3/papers.cfm?abstract id=3193576> accessed 31 October 2018, 27.
} 
SC on public blockchains so far. ${ }^{72}$ In the remainder of this section, however, we give a future outlook by suggesting that there could exist at least two possible scenarios where SC on public blockchains would foster new forms of economic exchange benefiting individuals and small economic players.

First, SC might help to create new forms of economic exchange that are more protective of privacy $^{73}$ and thereby increase the autonomy of consumers. Due to the fact that online transactions nowadays usually require relinquishing a significant amount of personal information to large intermediaries, ${ }^{74}$ and due to constant tracking of internet users through cookies and data analytics, ${ }^{75}$ users might prefer to transact online in a way that protects them better from their data being exploited. ${ }^{76}$ Transacting through SC on blockchain would allow users to give away only the amount of data that they are willing to give up, or that is strictly necessary to complete the transaction. ${ }^{77} \mathrm{As}$ put forward by Catalini and Gans, it would also allow them to charge the amount that they deem fit for giving away their data, or they could pay themselves for receiving a service that does not rely on the exploitation of data as revenue model. ${ }^{78}$

\footnotetext{
72 Kiffer et al. show, for example, that on the most popular public blockchain for SC, Ethereum, that more than $60 \%$ of contracts have never been interacted with. In addition, all SC on Ethereum are created by a very small number of users. See Kiffer et al, 'Analyzing Ethereum's Contract Topology' IMC '18, October 31November 2, 2018, Boston, MA, USA, $<$ https://mislove.org/publications/Ethereum-IMC.pdf $>$ accessed 12 April 2019.

73 This point is also made, for example, by Michèle Finck, 'Blockchains and Data Protection in the European Union', Max Planck Institute for Innovation \& Competition Research Paper No. 18-01, <https:// papers.ssrn.com/sol3/papers.cfm?abstract_id=3080322> accessed 5 June 2019.
}

74 The massive exploitative use of user data has recently led the German competition authority to impose restrictive measures on how Facebook can use user data, see $<$ https://www.bundeskartellamt.de/SharedDocs/ Meldung/EN/Pressemitteilungen/2019/07 022019 Facebook.html> accessed 11 April 2019. Others worries concern the use of user data on online marketplaces that could allow for personal pricing, thereby discriminating between various users based on their behavior and personal attributes. This could lead to a reduction in market trust and could harm consumers. See, e.g. OECD. Personalised Pricing in the Digital Era. Report of 20 November 2018, <https://one.oecd.org/document/DAF/COMP(2018)13/en/pdf $>$ accessed 11 April 2019.

75 Catalini, Gans, supra, note 21 . This would also further the objective of data sovereignty for consumers and citizens, see Finck, supra, note 73.

\footnotetext{
${ }^{76}$ See also Finck, supra, note 73, 8-9.

77 Catalini, Gans, supra, note 21.

${ }^{78}$ Ibid.
} 
Current legislation on e-commerce 79 and practices of online platforms force users to give away personal information by design. ${ }^{80}$ This can have benevolent aims, for example to ensure that users have recourse to redress through the ordinary court system or alternative dispute resolution systems. Nonetheless this comes with the cost of giving up significant amounts of personal data. As things stand, if there were no information duties and relinquishing of personal information, trust in e-commerce would be eroded. ${ }^{81}$ We suggest that SC on public blockchain could offer both: a large degree of privacy enhancing anonymity, ${ }^{82}$ while providing procedural safeguards based on no-party trust which would reduce risks for parties to such an extent that they would engage in economic exchange. With the development of privacy enhancing public blockchain based data exchange solutions like Datawallet, these ideas are also finding their way into the markets. ${ }^{83}$

Second, SC bear the potential of democratising trade in the sense that more small players and individuals can enter the market and engage in economic exchange. ${ }^{84}$ This is particularly true where market participants would usually need to rely on intermediaries to enter into economic transactions. ${ }^{85}$ One example would be the licensing of digital intellectual property rights. Where blockchains might provide the tools to prove the origins of a copyrighted work (which can be tagged with a unique digital fingerprint, and metadata regarding author, owner(s), etc could be attached to it) if registered on a blockchain, ${ }^{86} \mathrm{SC}$ could allow for transfers of licensing fees in 79 See for example the information duties for an online seller in Article 6 of the E-Commerce Directive
$2000 / 31$.

${ }^{80}$ Luca explains, for example, that while first generation online marketplaces such as Amazon or eBay showed very little information of buyer and seller to each other, second generation platforms include much more comprehensive user profiles, e.g. including pictures, and personal biographies (e.g. Uber or Airbnb). This is not necessarily a good thing, since discrimination on second-generation platforms has become a quite pervasive, and researched, problem. See Michael Luca, 'Designing Online Marketplaces: Trust and Reputation Mechanisms' (2017) Innovation Policy and the Economy 17, 77-93.

${ }^{81}$ Information duties in e-commerce were set up for the purpose of fostering trust in e-commerce, and so is the setting up of personal profiles on online platforms. Luca, 'Designing Online Marketplaces: Trust and Reputation Mechanisms’ (2017) Innovation Policy and the Economy 17, 77-93

82 Whether privacy is ultimately enhanced would always depend on how the blockchain system is designed. This point is stressed, for example, by Finck, supra, 73, 9. An example of a privacy-enhancing blockchain system in described in Guy Zyskind et al, 'Decentralizing Privacy: Using Blockchain to Protect Personal

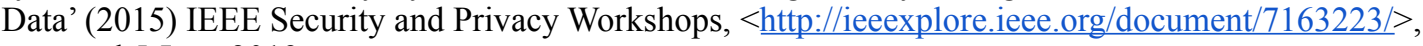
accessed 5 June 2019.

83 See Datawallet Whitepaper, <www.tokensale.datawallet.com/pdf/datawallet whitepaper.pdf $>$ accessed 7 June 2019. For further details on their ongoing work for more transparent and fair data exchange with the help of blockchain based SC, see Alex Norta, Daniel Hawthorne, Serafin L. Engel, 'A Privacy-Protecting Data-Exchange Wallet with Ownership- and Monetization Capabilities' (2018) International Joint Conference on Neural Networks Proceedings (IJCNN 2018), 1-8.

84 The description of the scenario stems from an exchange with Roger Brownsword.

85 See OECD, supra, note 70; Catalini, Gans, supra, note 21.

86 E.g. Digimarc Whitepaper $<\underline{\text { https://www.digimarc.com/docs/default-source/digimarc-resources/ }}$ whitepaper-blockchain-in-music-industry.pdf?sfvrsn=2> accessed 31 October 2018. 
respect of digital works between author/owner and user. ${ }^{87}$ Such projects have been already suggested in respect of music (e.g. Mediachain) ${ }^{88}$ and any digital IP in general. ${ }^{89}$ Currently, the copyright licensing relies on collaboration between national collecting societies and regularly does not provide right holders with the amount of revenues that they would be entitled to. ${ }^{90}$ Here again, trust would be generated by having clearly established property rights, and allowing parties that would not benefit from any other conventional trust mechanism (no common legal systems due to cross-border transactions, no mutual belonging to the same community, or knowledge about each other's internal preference system) to enter into direct small value exchanges across the globe.

The idea that SC help in creating desirable, legal, and competitive markets can still be challenged with the argument that SC are not perfect. SC are creatures of code. The code of any minimally sophisticated SC is likely to contain bugs, like any other computer programme, that will result in malfunctions. ${ }^{91}$ In light of this problem, it is argued that the perfect execution of a SC would be a myth in practice. ${ }^{92}$ Regularly malfunctioning SC would undermine trust in technology, and would increase transaction costs both ex-ante (since SC would need to be thoroughly tested) and ex-post (fixing problems that arise from a faulty SC).

While there is certainly room for cautionary arguments relating to the implementation of SC, the technical obstacles will likely be overcome in a not too distant future given the financial backing ${ }^{93}$ and brain power ${ }^{94}$ that is currently being poured into blockchain technology. In this respect, we think it is more important to further discuss and tease out the economic potential and competitive advantages of SC compared to already existing contract environments.

\footnotetext{
${ }^{87}$ See, however, for a critical assessment of such a possibility from a copyright law perspective Balázs Bodó, Daniel Gervais, João Pedro Quintais, 'Blockchain and Smart Contracts: The Missing Link in Copyright Licensing?' (2018) 26:4 International Journal of Law and Information Technology 311.

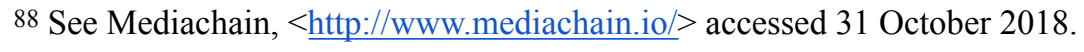

${ }^{89}$ See Entropia Universe DeepToken 2018 Whitepaper $<$ https://deeptoken.io/docs/ V6 MindArk Whitepaper_SINGLES.pdf $>$ accessed 31 October 2018. The long-term goal of this project is to create a global intellectual property exchange for IP in digital assets.
}

90 A report by Berklee suggests that between 20 to $50 \%$ of music payments do not make it to their rightful owners. See Berklee. Transparency and Payment Flows in the Music Industry (2015), < $\underline{\text { https:// }}$ www.berklee.edu/sites/default/files/Fair\%20Music\%20\%20Transparency $\% 20$ and $\% 20$ Payment $\% 20$ Flows $\% 20$ in $\% 20$ the $\% 20$ Music $\% 20$ Industry.pdf>

${ }^{91}$ Mark Giancaspro, 'Is a 'Smart Contract' Really a Smart Idea? Insights from a Legal Perspective' (2017) 33 Computer Law and Security Review, 830; Eliza Mik, 'Smart Contracts: Terminology, Technical Limitations and Real World Complexity’ (2017) 9 Law, Innovation and Technology 269, 293.

92 Mik, supra, note 88, 281.

93 Deloitte's 2018 Global Blockchain Survey shows, for example, that 39\% of more than 1000 respondent companies will invest more than $\$ 5$ million in the area of blockchain technology. This alone would amount to at least $\$ 1.95$ billion. See $<$ https://www2.deloitte.com/content/dam/Deloitte/cz/Documents/financialservices/cz-2018-deloitte-global-blockchain-survey.pdf>

94 A Glassdoor Report from 2018 shows that job openings requiring blockchain skills increased by $300 \%$ from 2017 to 2018 and pay $61.8 \%$ than the US median salary. See < https://www.glassdoor.com/research/risein-bitcoin-jobs/> accessed 11 April 2019. 


\section{Conclusion}

We asked in this paper what kind of trust underpins SC and under which circumstances would SC facilitate novel forms of economic exchange. Our argument was the following.

While we are familiar with how the first-party, peer-to-peer, and Leviathan trust mechanisms support economic exchange, these do not seem to be sufficient for characterising the way certain technologies like public blockchain based SC support trade. Next to trust in institutions, we can talk about trust in or the reliability of technology. In case of SC, this is built on the automated performance, decentralisation, and proofing mechanism. It makes it easier for parties relying on the technology to decide to enter into a relationship with each other. It also enables them to enter into relationships on the basis of a minimal level of acquaintance with the other party. Just like in a legal or community environment, these implications arise from the parties' awareness that the other party is bound by that same technological environment and is, accordingly, subject to the automation, procedures and sanctions that the environment prescribes.

In economic terms, SC could reduce transaction costs to such an extent that people would be willing to enter into beneficial economic relations through a market system in a form that they could not in the absence of SC. While there is room for caution relating to the possibility of using $\mathrm{SC}$ for illegal or anti-competitive purposes, there is also room for supporting the valuable trade that could occur in the no-trust contracting environments where it was not possible before. Upon further study, this might lead us to developing much-needed tools for increasing the autonomy of consumers and small economic players, or creating markets where risks of theft or the small amount of value transferred would have prevented economic exchange from happening. 